\title{
Effects of performance goals and social norms on academic dishonesty in a test
}

\author{
Martin Daumiller ${ }^{*}$ (D) and Stefan Janke ${ }^{2}$ \\ 'Department of Psychology, University of Augsburg, Germany \\ ${ }^{2}$ University of Mannheim, Germany
}

Background. Previous research has shown that achievement goals affect the frequency of academic dishonesty. However, mixed findings suggest that especially the effect of performance goals might depend on contextual factors.

Aims. We wanted to investigate whether crucial aspects of the achievement situation
influence the magnitude of the effect of performance goals (here: focused on appearance)
on dishonesty. Specifically, we propose that social norms regarding the acceptance of
dishonesty moderate the positive effect of performance goals on academic dishonesty.

Sample. We sampled 105 German university students. They were teacher trainees, mostly in their first year at university and on average $20.6(S D=3.6)$ years old $(72.4 \%$ female).

Method. We conducted a 2 (induced appearance goals vs. no goal induction) $\times 2$ (cheating confederate vs. no observable cheating behaviour by this person) experiment. $A$ manipulation check confirmed that the manipulation of appearance goals was successful. Cheating behaviour was observed by a confederate student and subsequently classified by two raters. Additionally, participants' dishonesty in self-presentation questions was measured using deviations from baseline measures.

Results. The induction of appearance goals only led to increased cheating when the social norm suggested that cheating behaviour was an acceptable way to increase performance (i.e., cheating confederate condition). For deceiving, we found a positive main effect of appearance goals. Appearance goals mediated these effects from goal manipulation on academic dishonesty.

Conclusions. Taken together, our results highlight that the mixed findings on the effect of performance goals on academic dishonesty might be due to uninvestigated moderators such as social norms. Future research should build on these findings to identify additional moderators.

'Everyone's doing it' describes the dishonest behaviour of students well. The majority of students report that academic dishonesty is very prevalent within educational contexts (Stephens \& Gehlbach, 2007). For instance, studies show that between half and two thirds of university students cheat at least once over the course of their studies (Bernardi et al., 2004; Hrabak et al., 2004; McCabe, 2005; Rettinger, Jordan, \& Peschiera, 2004; Teixeira \& Rocha, 2010). Academic dishonesty can be displayed in a variety of ways encompassing

This is an open access article under the terms of the Creative Commons Attribution-NonCommercial License, which permits use, distribution and reproduction in any medium, provided the original work is properly cited and is not used for commercial purposes.

*Correspondence should be addressed to Martin Daumiller, Department of Psychology, University of Augsburg, Universitätsstr. 10, Augsburg 86159, Germany (email: Martin.Daumiller@phil.uni-augsburg.de). 
(1) the specific, intentional breaking of rules as well as (2) lying and omitting facts. The term 'cheating' often refers to both aspects. As both forms vary in their publicity and the risk of getting caught, different mechanisms behind them are plausible. Therefore, we keep them conceptually separated by referring to the former as cheating (e.g., copying answers of others in a test) and to the latter as deceiving (e.g., lying or creating a mistaken impression). Both cheating and deceiving can result in high costs for the involved students and society as a whole (e.g., missed learning opportunities, expulsion, unjustified credentials, hiring of less qualified individuals, undermined confidence in our educational system, see also Keith-Spiegel \& Whitley, 2012) and might be especially harmful because there is a strong link between an individual's dishonesty at university and at the workplace later on (Hrabak et al., 2004; Lawson, 2004; Nonis \& Swift, 2001). As such, it is important to understand which factors elicit cheating behaviour within students. Prior research on achievement motivation has mainly tried to address why academic dishonesty occurs. Throughout this, performance goals (focused on validating or demonstrating competence) have come under suspicion of eliciting academic dishonesty. However, findings on this relationship are mixed at best. For this reason, we propose that a greater focus should be placed on the circumstances under which students cheat and deceive. More specifically, we propose that social norms moderate the supposedly positive effects of performance goals.

\section{Achievement goals and social norms as frameworks to explain academic dishonesty}

In essence, cheating and deceiving are motivated behaviour because they entail intentionally violating pre-set rules in order to gain an advantage or to increase the likelihood of success (Murdock, Hale \& Weber, 2001). Both of them are moral as well as social decisions (O'Rourke et al., 2010). As such, it is highly plausible that individuals differ in the strength to which they consider this behaviour functional for the attainment of their desires. Especially in achievement situations, this functionality is likely directly associated with individual differences in achievement goals.

Achievement goal theory distinguishes personal aims that are focused on different (desired or undesired) results or end states that are centred on different perceptions of competence in achievement situations (Elliot, 2005; Hulleman, Schrager, Bodmann, \& Harackiewicz, 2010). Originally, researchers distinguished between learning goals (focused on the learning process, improvement, and skill development) and performance goals (focused on appearance and performance relative to others; e.g., Dweck \& Leggett, 1988). Later, theorists added a valence dimension to these goals, that is, whether individuals try to approach or avoid the corresponding outcomes, leading to learning approach, learning avoidance, performance approach, and performance avoidance goals (Elliot \& McGregor, 2001). More recently, researchers also proposed that performance goals should be distinguished regarding whether they are focused on the demonstration and affirmation of competence to an audience (appearance goals), or whether performance is defined based on normative social comparisons (normative goals; see Hulleman et al., 2010; Urdan \& Mestas, 2006). In the present work, we take this distinction into consideration and empirically only focus on appearance goals. We are doing so to be conceptually very precise and to allow for a clear interpretation and comparability of our results (see Daumiller, Dickhäuser, \& Dresel, 2019; Hulleman et al., 2010). Theoretically, we expect appearance goals to be especially relevant for dishonest behaviour. This is because individuals who strongly focus on their appearance may value cheating as a valid strategy to this end (Janke, Daumiller, \& Rudert, 2019). 
The relevance of goals on academic dishonesty has not only been examined on the personal level (i.e., personal achievement goals) but also on the classroom level by focusing on classroom goal structures, conceptualized as a shared perception of the motivational climate in the classroom (Ames \& Ames, 1984). They are created and modified by the surrounding (classroom, school) context as well as the actions and characteristics of those within the classroom (both teachers and students), most notably teachers' instructional practices (see Lüftenegger, Tran, Bardach, Schober, \& Spiel, 2017). For instance, a performance goal structure reflects that students believe that social comparisons, grades, and competition are emphasized in their classroom. Such a goal structure is associated with increased academic dishonesty and a higher justifiability and acceptability of cheating (Murdock, Miller, \& Goetzinger, 2007; Murdock, Miller, \& Kohlhardt, 2004; see Anderman, 2007, for an overview). While classroom goal structures may be of high interest for understanding classroom effects, they do not sufficiently explain the processes at the individual level. To this regard, it is very plausible that a performance goal structure may elicit cheating through the facilitation of personal performance goals (Meece, Anderman, \& Anderman, 2006). This direct association between personal achievement goals and academic dishonesty is of high interest because it explains the underlying psychological processes and has implications beyond the educational context in primary and secondary education (e.g., also for non-classroom contexts).

Previous research has consistently documented negative associations between learning (approach and avoidance) goals and the occurrence of academic dishonesty (e.g., Jordan, 2001; Marsden, Carroll, \& Neill, 2005). This is plausible considering that such actions likely lead to wrong self-assessments and missed learning opportunities and, as a result, would hinder the aspired true understanding and growth of an individual's own competence. In contrast, it would be logical to assume that performance goals facilitate cheating and deceiving because these behaviours can provide an additional advantage in the striving for competence demonstration (e.g., to win, or not to lose, possibly at any cost, Van Yperen, Hamstra, \& van der Klauw, 2011; see also Schwieren \& Weichselbaumer, 2010). This should be especially true when performance goals are characterized by an appearance focus because these goals orientate the individual towards judgement by others (e.g., teachers). Given that this judgement normally depends on a display of performance, it is likely that individuals with strong appearance goals put more weight on the outcomes of their actions rather than on the progress that leads to these outcomes. In turn, this could elicit the view that the ends justify dishonest means (see Janke et al., 2019, for a similar argument).

Although theoretically sensible, the empirical findings for performance goals are mixed (see Table 1 for an overview of the corresponding research works). The great majority of studies that investigated personal performance goals (rather than extrinsic or grade orientation, which are conceptually related but not the same construct, see Hulleman et al., 2010) did not find statistically significant associations between these goals and academic dishonesty (in total: 16 nil findings, 4 [partially] positive associations, and 6 [partially] negative associations). Interestingly, the effects were more mixed for performance avoidance than for performance approach goals in the sense that more empirical evidence exists for positive but also for negative associations with academic dishonesty. This pattern of results for personal performance goals presents us with a gap between the theory (positive association between performance goals and academic dishonesty stands to reason) and empirical findings (mostly nil findings). We propose this may reflect that the perceived utility of cheating for the attainment of personal 


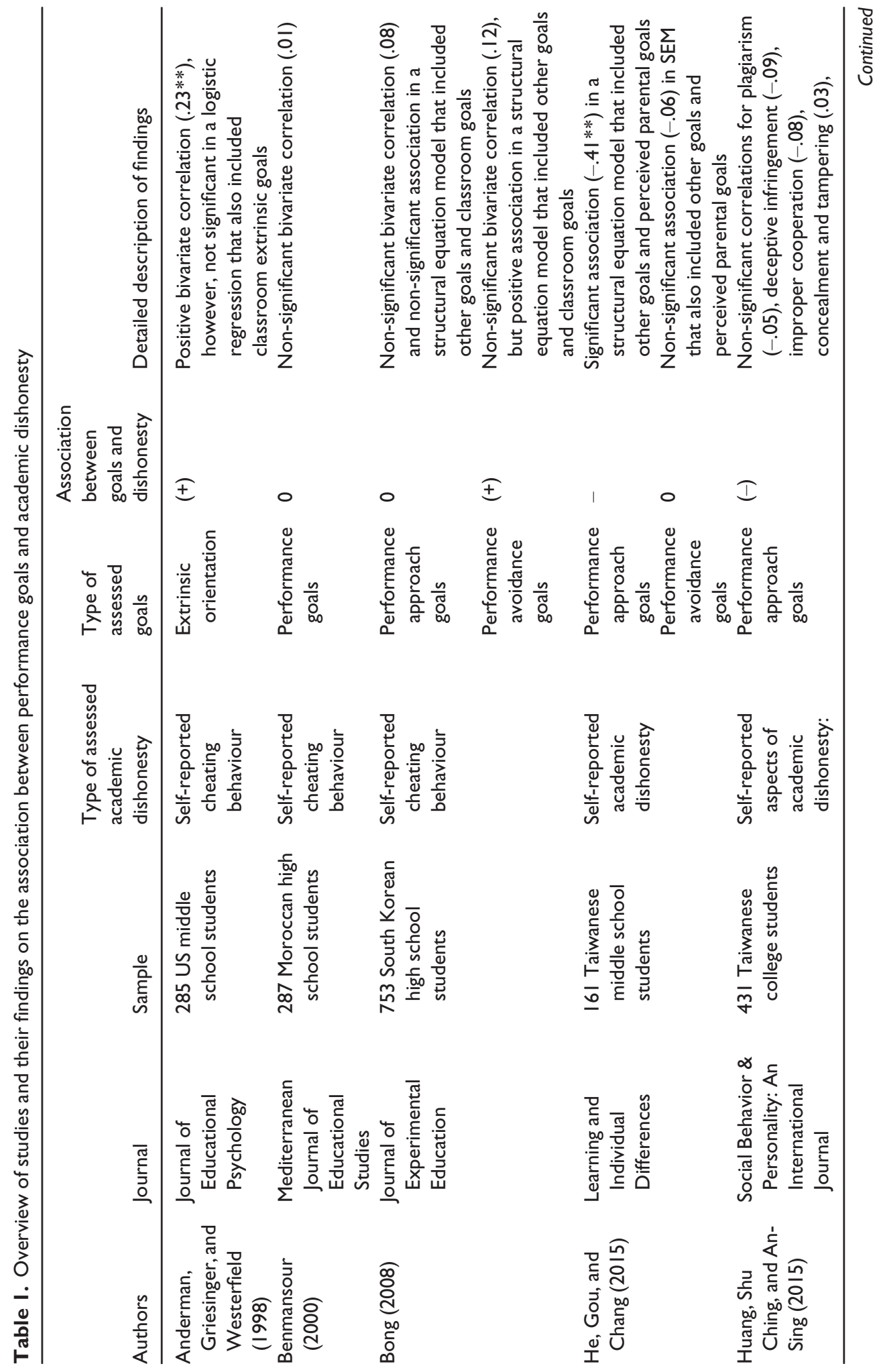




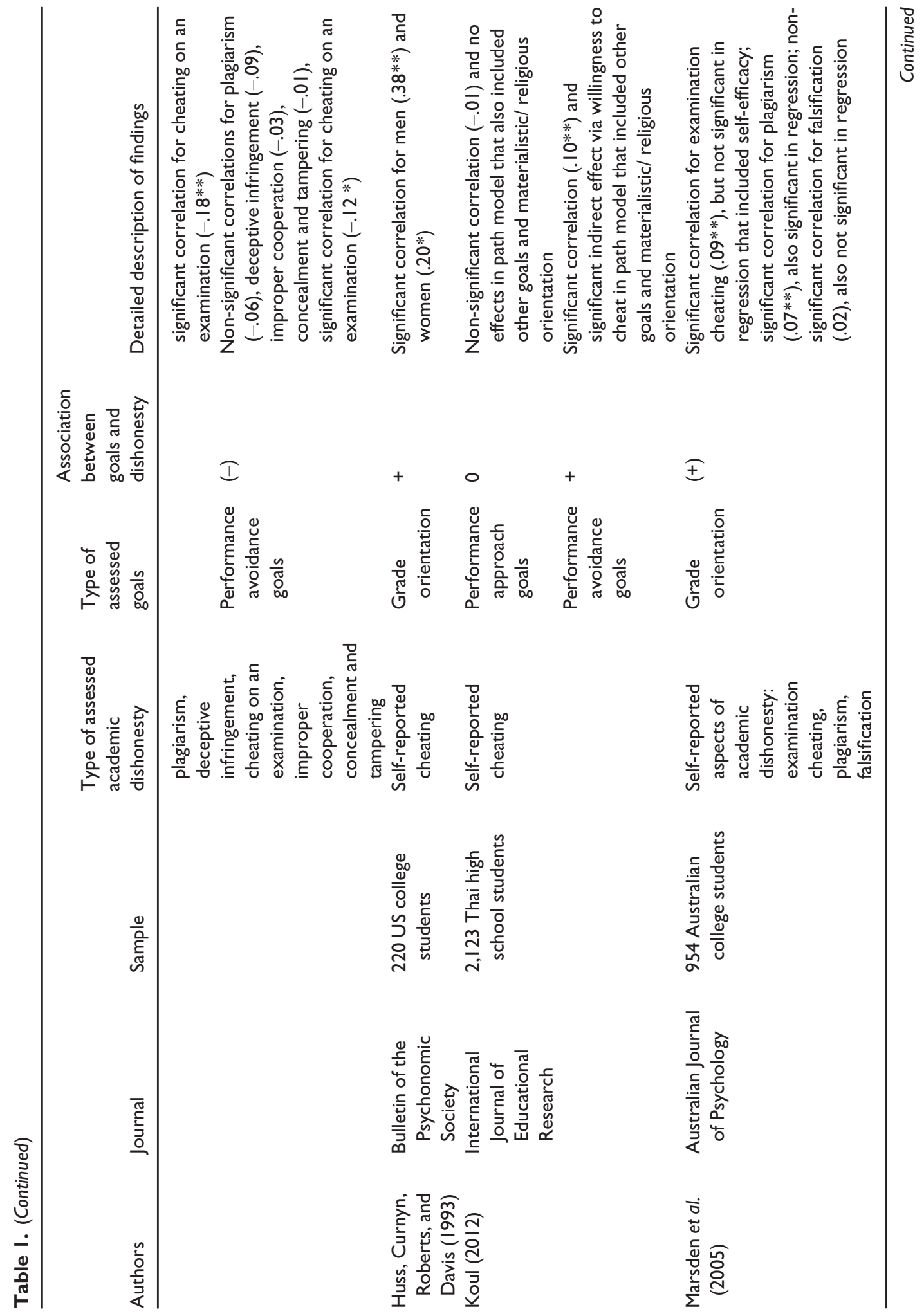




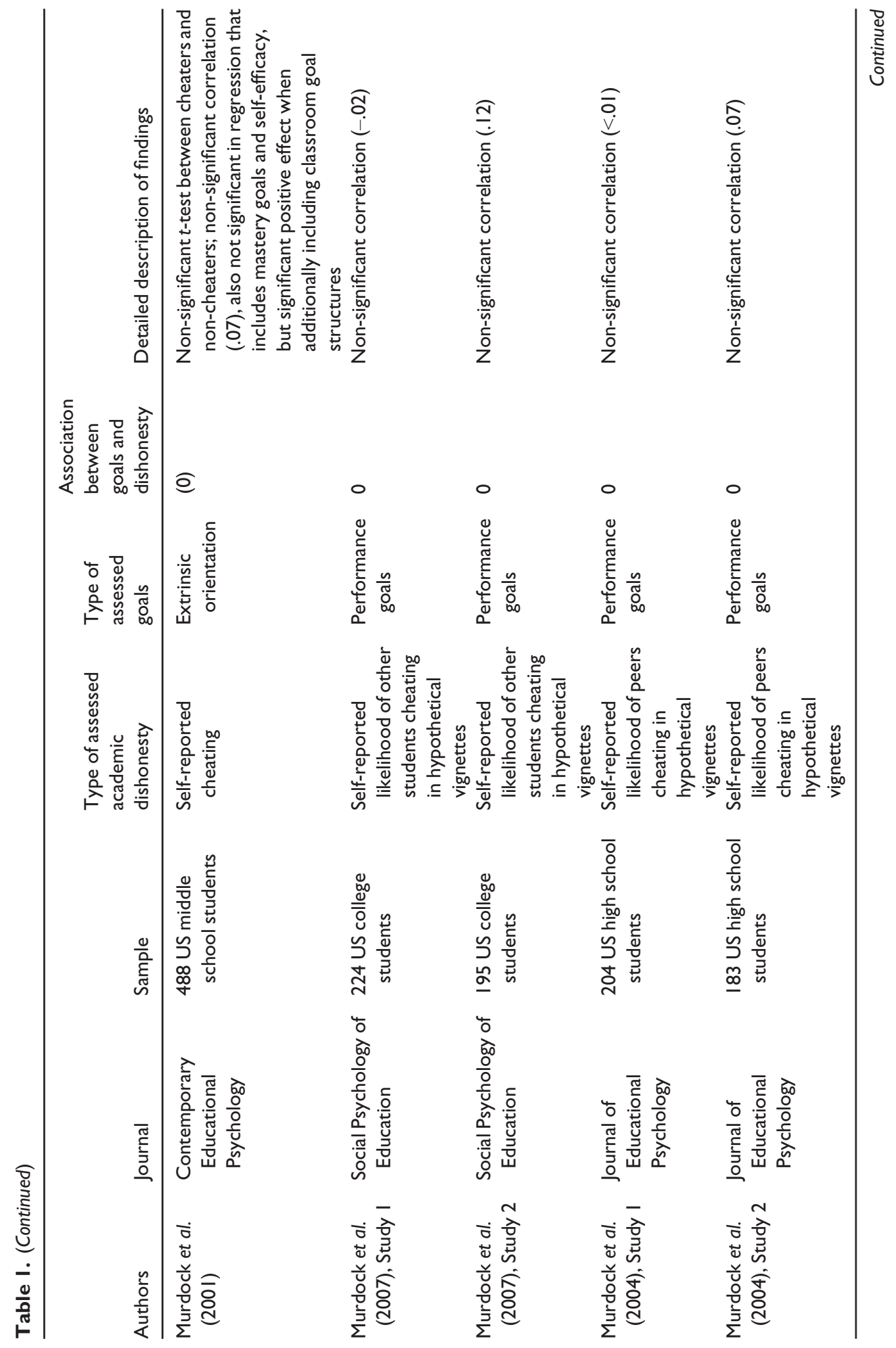




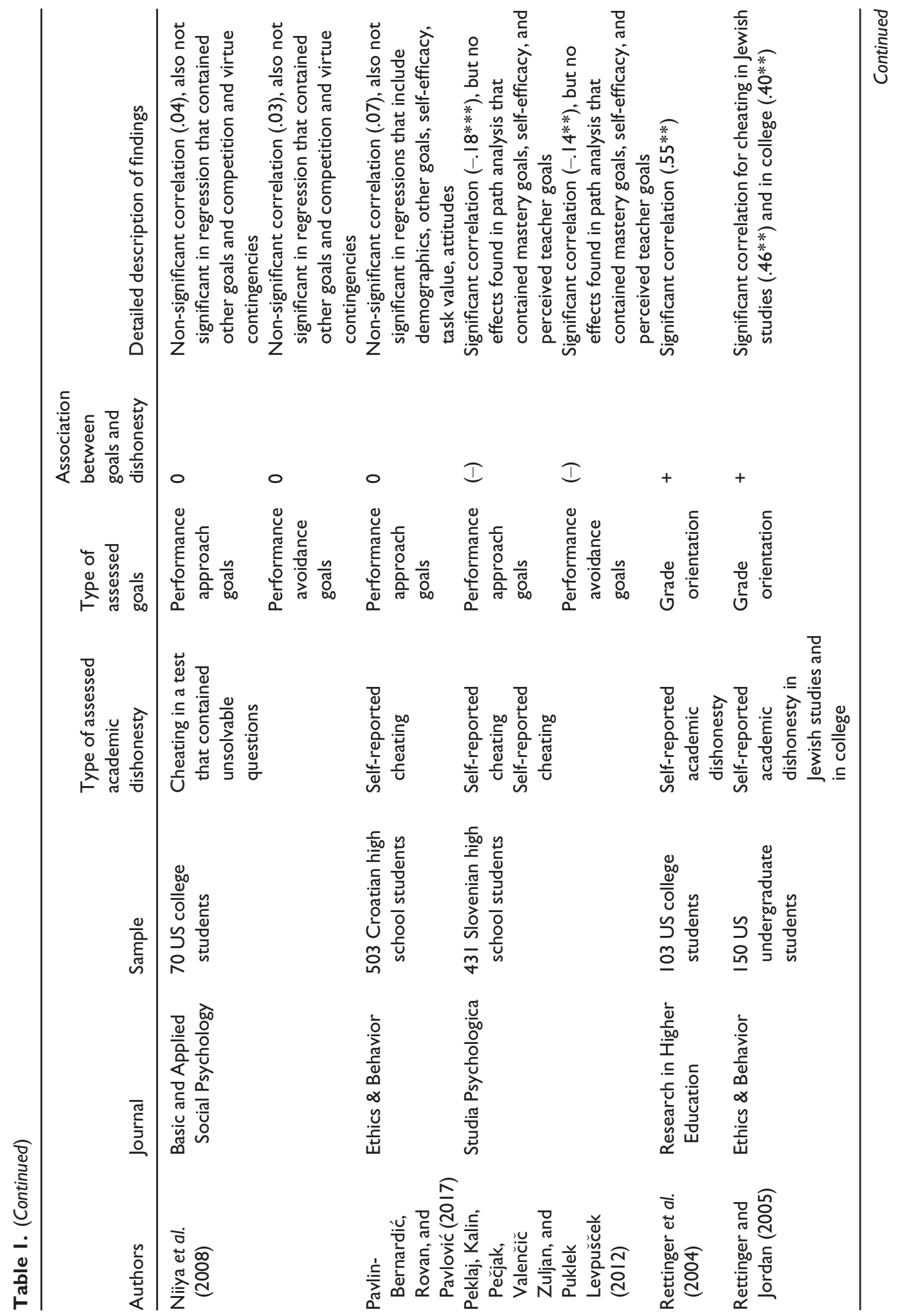




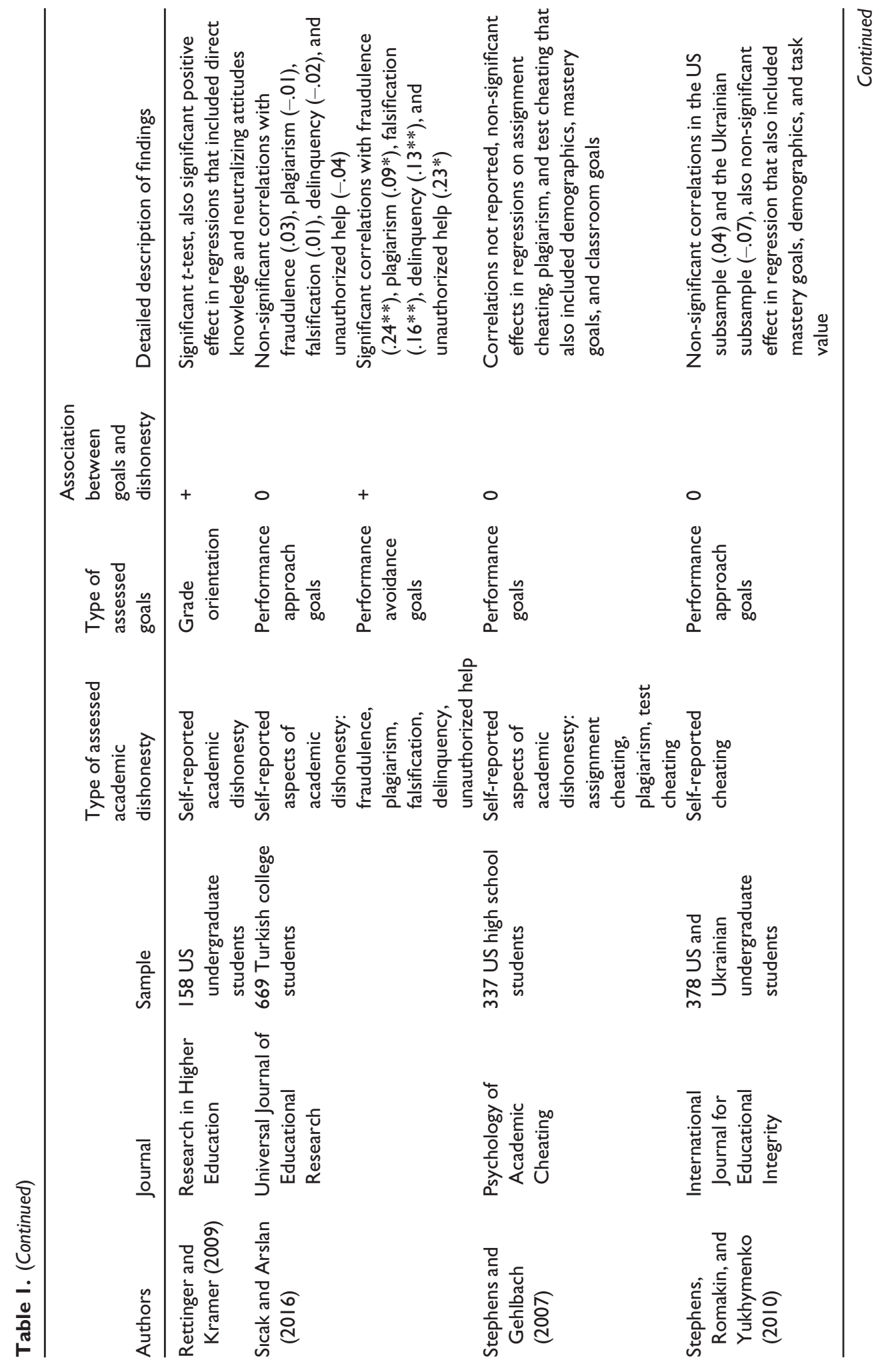




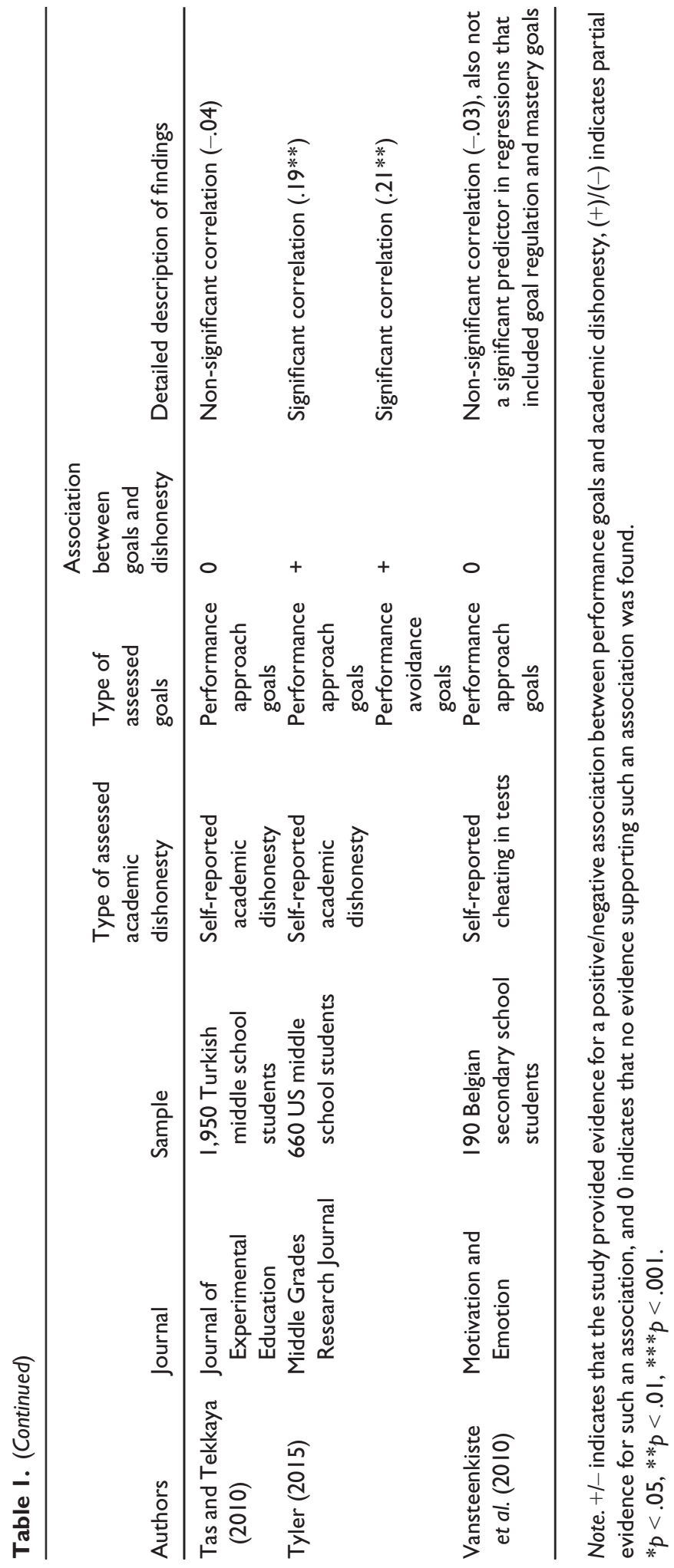


performance goals may depend on factors rooted in the respective achievement situation that have not yet been investigated within the theoretical framework of achievement goal theory.

To this end, we expect that especially social norms could influence the relationship between performance goal adoption and engagement in cheating because social norms dictate the perceived appropriateness of cheating as well as the perceived likelihood of punishment (Cialdini \& Trost, 1998; Gino, Ayal, \& Ariely, 2009). Here, we assume that individuals are especially inclined to engage in cheating behaviour when they adopt performance goals and the social norm indicates that such behaviour is acceptable. This reasoning is very much in line with the Theory of Planned Behavior (Ajzen, 1991), which would also lead to the assumption that the intention to cheat depends, on the one hand, on individual motivational factors that are highly relevant for individual attitudes towards cheating, and on the other hand, on subjective norms (Simkin \& McLeod, 2010). The Theory of Planned Behavior also acknowledges the importance of perceived behavioural control for behavioural intent (Ajzen, 1991). However, we will merely focus on social norms and personal motivation as achievement situations are characterized by individuals pursuing goals that make their efforts meaningful and the presence of others (Poortvliet, Janssen, Van Yperen, \& Van de Vliert, 2007) - with achievement situations in education in particular typically being characterized by perceived possibilities to cheat due to limited resources of teaching personnel.

Considering social norms and personal motivation as driving factors behind academic dishonesty can also be very fruitful because such an approach moves past simplified traitbased explanations claiming that only students with problematic personality traits or unfavourable motives would engage in such behaviour (see Whitley, 1998, for a similar argument). Considering chiefly trait-based factors is not only insufficient (given the high prevalence of dishonest behaviours) but also limits the applicability of behavioural modification as personality is rather stable.

\section{Peer cheating and perceived social norms}

We propose that social norms regarding peer cheating matter when investigating the impact of performance goals on dishonest behaviours. While goals may represent the motivational drive to find such behaviours attractive (but not necessarily execute it), social norms could influence whether individuals gauge that these behaviours may lead to personal acclaim or potentially to severe repercussions like social ostracism (Fehr \& Fischbacher, 2004; Rudert, Sutter, Corrodi, \& Greifeneder, 2018) and likely serve as a cue for the normative appropriateness of such behaviours (Graham, Monday, O'Brien, \& Steffen, 1994; Kibler \& Kibler, 1993; McCabe, Treviño, \& Butterfield, 1999).

First evidence that at least the personal adherence to social norms on cheating may influence the relationship between performance goals and cheating was provided by Janke et al. (2019). These authors found in moderation analyses that the less important it was for researchers to adhere to scientific standards, the stronger the association between appearance approach goals and questionable research practices.

Often the easiest way to evaluate the social norms within an achievement situation is mere observation, in our case the literal observation of others' cheating (see O'Rourke et al., 2010, for survey results on how having seen others cheat is associated with one's own academic dishonesty). Such observations are positively correlated with one's own increased cheating behaviour (Genereux \& McLeod, 1995; Jordan, 2001; McCabe \& Treviño, 1997; O'Rourke et al., 2010; Rettinger \& Kramer, 2009). Student explanations for 
cheating also often include elements of social comparison and behaviours of other students (Haines, Diekhoff, LaBeff, \& Clark, 1986; McCabe, Treviño, \& Butterfield, 2001), which once again underlines the importance of such perceived social norms for the justification of cheating behaviours. However, this also points to an important limitation of the previous, mostly correlational studies: Reporting that other students cheat as well is an important neutralization strategy (Sykes \& Matza, 1957) to rationalize one's own behaviour (O'Rourke et al., 2010), because it allows students to relieve themselves of responsibility for their actions. Consequently, it is likely that asking students about their own cheating behaviour and such behaviours of others in cross-sectional studies will yield associations due to unconscious justifications. This limitation of previous works needs to be overcome with experimental designs.

Another limitation of prior research is that academic dishonesty was often assessed with self-report questionnaires (see Table 1, and Giluk \& Postlethwaite, 2015). Thus, we see a strong need for more objective assessments (e.g., by observing cheating behaviours). To this end, the inclusion of deceiving (e.g., dishonest self-presentation in personality questionnaires; see Guadagno, Okdie, \& Kruse, 2012) allows empirical measurement of an additional aspect of academic dishonesty and pursuit of another non-strictly self-reported operationalization of this aspect as another contribution to the literature.

\section{Research questions and hypotheses}

In sum, we argue that individuals need the motivation as well as the circumstances to engage in academic dishonesty. We presumed that appearance goals and social norms (expressed by cheating behaviour of others) would influence dishonest behaviours (i.e., cheating and deceiving) as follows:

1. We expected increased dishonest behaviours in students with induced appearance goals (main effect of appearance goals).

2. We expected increased dishonest behaviours in students with an induced social norm of cheating acceptability (main effect of social norm).

3. We expected appearance goals to especially lead to increased dishonest behaviours when the social norm makes this behaviour seem acceptable (interaction of appearance goals and social norm).

\section{Method}

To explain the inconsistent effects often found for performance goals and to overcome the limitations of previous, correlational studies, we conducted a $2 \times 2$ factorial experiment in which we manipulated appearance goals and the social norm. As dependent variables, we included cheating (e.g., copying answers of others in a test) and deceiving (e.g., presenting oneself in a different light in an interview) as aspects of academic dishonesty (Stephens, 2008). ${ }^{1}$ We pre-registered our research questions, study design, and planned analyses prior to data collection (Aspredicted ID: 7116; https://aspredicted.org/eq6wf.pdf).

\footnotetext{
' While these two aspects constitute actual deceiving behaviours that were measured externally (using observers and deviations within the participants' answers), we originally also wanted to include participants' cheating behaviour in the form of a single selfreport question after the test. However, due to low variance in this variable, we could not use it for our analyses and as such do not report it in this manuscript.
} 
Recruitment

Baseline

Factor 1:

Performance Goal

Manipulation (Yes or No)

Manipulation Check

Cheating Opportunities While Working on the Knowledge Test

Factor 2: Social Norm Manipulation (Yes or No) to be used in an assessment center

Online baseline questionnaire including personality items

- Select a date in three weeks' time $\rightarrow$ individual work on the test

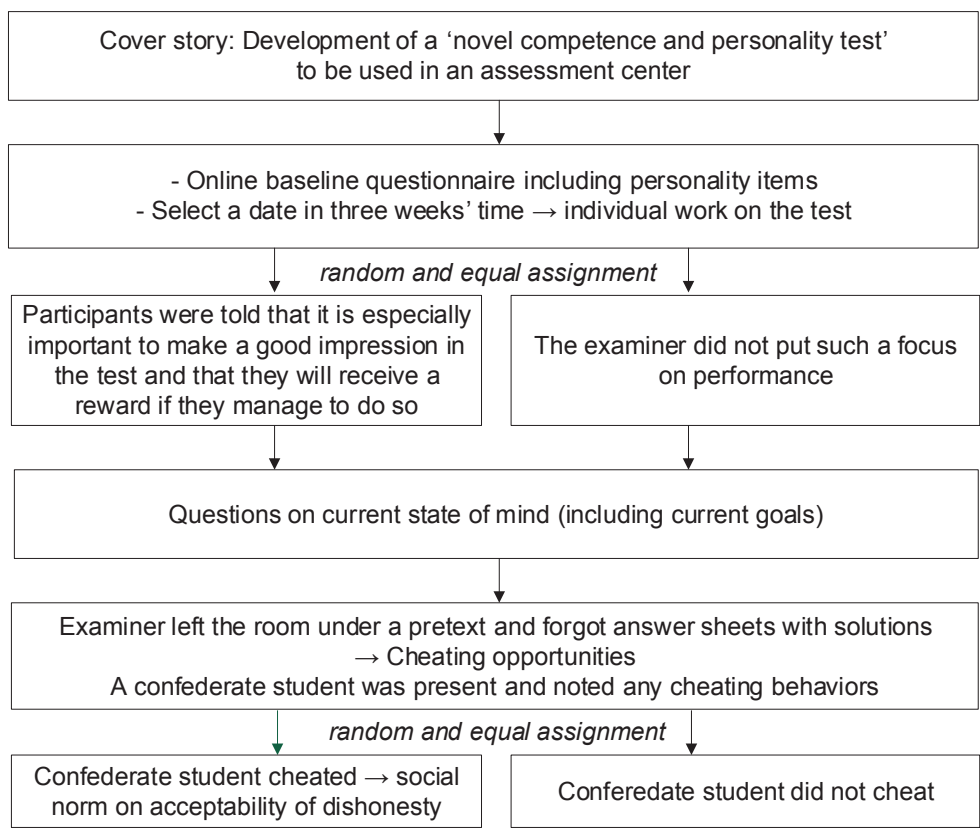

Figure I. Procedure of the experiment.

Data were collected during 11-22 December 2017. All data and codes that support the findings of this study are provided in an open access repository (https://osf.io/3w $7 \mathrm{ra} /$ ).

\section{Procedure and experimental manipulation}

Our experiment (see Figure 1 for an overview) consisted of four groups: a control group $(n=26)$, a group that only received an appearance goal instruction $(n=26)$, a group in which we induced a social norm based on another student cheating $(n=25)$, and a group with both an appearance goal and a social norm manipulation $(n=28)$.

We recruited students to participate in a 'novel competence and personality test' and told them that we wanted to develop this test to be used in an assessment centre. When signing up for the study, we asked the students to fill out a baseline questionnaire online. Afterwards, they could select a date in 3 weeks' time, on which they were invited to a separate room to individually work on the test. Before working on the test, the participants answered some questions on their current state of mind (including their current goals). Participants were then randomly and equally assigned to one of four groups. The examiner told half of the participants that it was especially important to make a good impression on the test and that they would receive a reward if their answers in the test were impressive (induction of appearance goals), while the other half of the participants received no such information on a performance-based reward system. Throughout the test, another (confederate) student was present. In order to be perceived as an ingroup confederate (see Gino et al., 2009, for how outgroup members might evoke reverse effects on academic dishonesty), we used a confederate student from the same age and study programme. The participants were told that this fellow student missed her regular appointment and that, as an exception, she was allowed to work on her test at the same time as the participant. In reality, this confederate student 
observed and rated the cheating behaviours of the participant (by taking notes on the knowledge test sheets that she pretended to be working on). After the instruction, the examiner left the room under a pretext and told the participants that she would be back in ten minutes. She left the room hastily and forgot the answer sheets with the correct solutions on her desk in front of the participants, so that opportunities for cheating behaviours were given. In both the control group and the group that received the appearance goal instructions, the confederate student used this cheating opportunity for half of all runs (by visibly taking the solution sheet on the desk in front of them to check some of the answers and putting it back) and as such induced a social norm on the acceptability of dishonesty in this achievement situation.

During the test, the participants had to answer 23 general knowledge questions with an open and closed response format (Internal consistency: McDonald's Omega, $\omega_{\mathrm{H}}=.58$ ) as well as 14 personality and social desirability items (the complete test is included as Supporting Information). The knowledge questions were chosen based on a selfconstructed pool of items inspired by general knowledge tests and quizzes. This pool of items was previously piloted with eight students, and we chose those items that were moderately difficult and fitted well with the cover story.

\section{Sample}

In total, 105 German university students participated in the study. All of them were teacher trainees, mostly in their first year of university $(10 \%$ were in their second year or higher). On average, they were $20.6(S D=3.6$ ) years old $(72.4 \%$ female). Demographics for the experimental groups were as follows: control group: $58 \%$ female, mean age: 19.8 years, appearance goals group: 85\% female, mean age: 21.0 years, social norm group: $64 \%$ female, mean age: 21.8 years, achievement goals and social norm group: 82\% female, mean age: 19.8 years. We found no statistically significant differences between the experimental conditions regarding gender, $\chi(3)=6.97, p=.07$, and age, $F(3,104)=1.75, p=.16$.

\section{Measurements}

Appearance goals

Immediately after the instructions, we presented the participants with two items from the academic achievement goal questionnaire from Daumiller et al. (2019) to measure current appearance approach goals ('In the following test, my goal is to be perceived as competent', 'In the following test, my goal is that it is noticed how good I am'; $\omega_{\mathrm{H}}=.81$, Spearman-Brown $=.81$ ). Daumiller et al. (2019) demonstrated that their appearance approach goal scale can be distinguished from normative goals. We decided to use only two instead of all four items to avoid making the possibility of adopting appearance goals too salient, which would have endangered the experimental manipulation. We chose the two items with the best item-scale associations and clear face validity from the original scale to yield a measure that can still adequately assess appearance approach goals. In addition to these two items, we included other questions at this point (regarding the participants' current state and their expectations regarding the test, such as: 'I am currently feeling attentive and fit', 'I already have some experience with assessment center tests') so that the appearance goal items aligned well with the provided 
explanation that we were interested in several aspects of participants' state of mind when answering the test.

\section{Cheating}

The knowledge test contained specific knowledge questions and selected items from the baseline questionnaires. Possible cheating behaviour when working on this test was observed by the confederate student and written down in detail on the answer sheet. Based on this description, two raters classified this behaviour as cheating or not $(\kappa=1)$. Cheating behaviours encompassed looking at the answer sheet, peeking at other students' answers, asking the confederate student, and using mobile phones to search for the correct answers.

\section{Deceiving}

We calculated difference scores of participants' answers to personality questions as was done by Guadagno et al. (2012) to operationalize participants' extent of deceiving. Specifically, participants assessed personality traits (Big Five, Rammstedt \& John, 2005, and Dark Triad, Küfner, Dufner, \& Back, 2014) as well as social desirability (Musch, Brockhaus, \& Bröder, 2002) in the baseline. Theoretically, these constructs can be expected to be stable over the time span between the baseline and the test. We then included 14 items from these scales in the assessment centre test. Thereby, we chose those items for which we expected that participants would be most prone to answer in a socially desirable way when wanting to present themselves more favourably in the assessment centre test (i.e., deceiving). If participants did not fill out a personality question in the test, but answered one of the subsequent questions, we considered this person to have left out the respective question intentionally indicating deceiving (this was, on average, the case for $9.00 \%$ for the answers). We calculated the average deviation in the social desirability and personality items between the test and the baseline as the final deceiving measure (positive/negative values indicating a more/less favourable presentation of oneself during the test; $\left.\omega_{\mathrm{H}}=.64\right)$.

\section{Analyses and missing values}

All analyses were conducted with Mplus using the weighted least square mean and variance adjusted estimator (WLSMV) for the models with the dichotomous outcomes and otherwise the maximum likelihood estimator with robust standard errors (MLR). To evaluate the model fit, chi-squared was used as an absolute fit index, the Tucker Lewis index (TLI) as a relative fit index that also adjusts for parsimony, and the Root Mean Square Error of Approximation (RMSEA) and the comparative fit index (CFI) as noncentralitybased indices. Following Schermelleh-Engel, Moosbrugger, and Müller (2003), we considered RMSEA $\leq .05$, CFI, TLI $\geq .97$ as a good model fit.

We regressed cheating or deceiving (as dependent variable) onto two dummy-coded variables representing the experimental factors and their interaction term each to investigate the effects of the experimental manipulations. Afterwards, we estimated an overall moderated mediation model, analysing the effects from goal manipulation, via appearance goals (mediator), onto cheating and deceiving (two dependent variables) with the latter two effects moderated by the social norm. Moderated mediation was tested following Hayes (2018), estimating bootstrapped conditional indirect effects (using 5,000 
replications). The null hypothesis of no indirect effect is rejected if the confidence interval does not include zero. We report unstandardized coefficients for the moderated mediation model to allow a clear interpretability, particularly regarding the indirect effects.

There were relatively few missing values: Eight participants did not report their year at university, and for nine participants, we had no data from the baseline (because they either did not participate in it or their information could not be matched). A Missing Values Analysis indicated that Little's (1988) test of Missing Completely at Random (MCAR) was not significant, $\chi^{2}=33.67, d f=35, p=.53$. This implies that there was no evidence to suggest that the data were not MCAR. We dealt with missing data by using the FIML estimator and the EM-algorithm for all analyses (Peugh \& Enders, 2004). At the very end of the experiment, the participants were questioned on what they believed to be the research objectives of the study. Only one student correctly assessed the research aim and was consequently excluded from all analyses.

\section{Results}

\section{Descriptive results and manipulation check}

In total, 41 out of 105 students cheated in the test. On average, the non-cheaters answered $44 \%$ of the knowledge questions correctly (range: 19-85\%) with each student scoring 17$78 \%$. Cheaters answered on average $49 \%$ of the questions correctly (however, their knowledge test scores cannot sensibly be compared to the non-cheaters' test scores, as we do not know about students' initial knowledge levels and those who feel that they are not doing well on their own are more likely to cheat; Murdock \& Anderman, 2006). The participants generally presented themselves more favourably in the personal questions that were used for the deceiving measure in the assessment-situation than in the baseline questionnaire (on average 0.32 answer options per item, $S D=0.75$, range: -1.6 to 2.8 ).

A $t$-test as a manipulation check indicated that students who received the achievement goal instruction reported significantly stronger appearance goals than those who did not receive such an instruction, $M=5.54, S D=1.30$, versus $M=4.55, S D=1.64$; $t(103)=-3.42, p<.001$, Cohen's $d=0.66$. A correlation matrix of all reported variables is included as Supporting Information.

\section{Influence of the experimental manipulation on cheating and deceiving}

For cheating (prevalence in control group: 38\%, goals only group: $35 \%$, social norm only group: $24 \%$, goals and social norm group: $61 \%$ ), we found no significant main effect of the appearance goal condition $(\beta=-.18, p=.31)$ or for the social norm condition $(\beta=-.04$, $p=.83$ ). However, the interaction between the two experimental manipulations was significant $(\beta=.44, p<.05)$. This indicates that students were only more likely to cheat when they were prompted to adopt appearance goals and the confederate student was cheating (Figure 2).

For deceiving (magnitude in control group: $M=0.13, S D=0.77$, goals only group: $M=0.57, S D=0.70$, social norm only group: $M=0.24, S D=0.60$, goals and social norm group: $M=0.33, S D=0.91$ ), we found a main effect of the appearance goal manipulation $(\beta=.30, p<.05)$. However, we neither observed a significant main effect of the social norm condition $(\beta=.08, p=.56)$ nor an interaction between the two conditions $(\beta=-.20, p=.24)$. This means that students deceived more when their appearance goals 


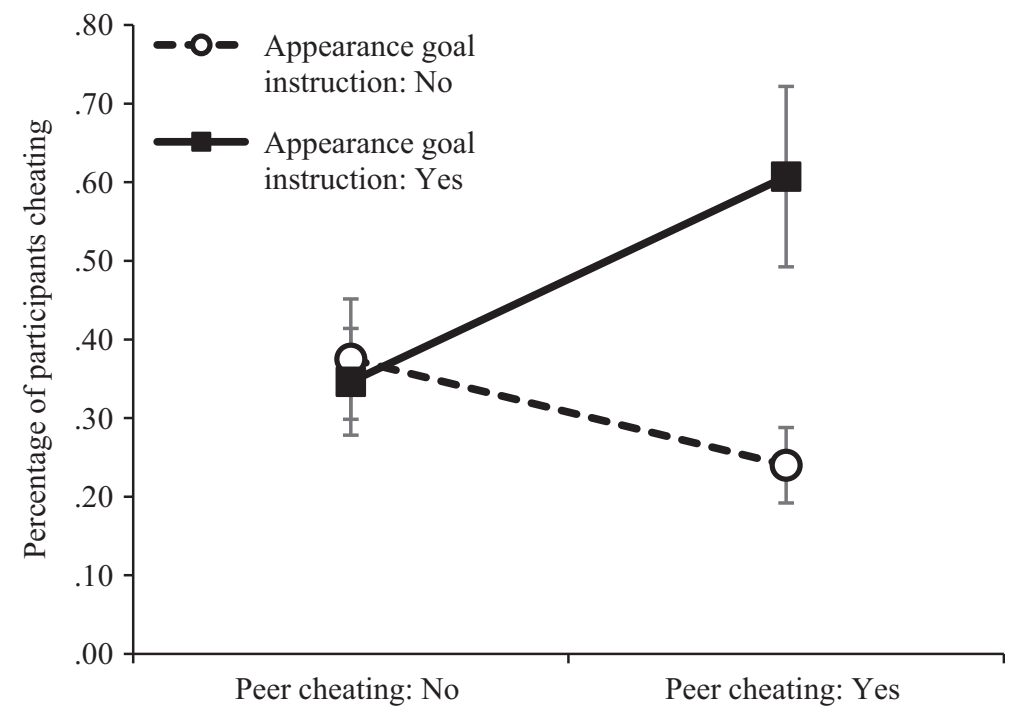

Figure 2. Effect of the experimental manipulation on cheating in the knowledge test (presented are means and their standard errors for the different experimental conditions).

were stressed in the instruction, but that the confederate student additionally cheating did not influence this effect.

\section{Overall moderated mediation model}

The overall moderated mediation model (Figure 3) fit the data well and indicated, in line with the previous analyses, that the social norm significantly influenced the relationship between appearance goals and cheating, while for deceiving, there was a positive main effect for appearance goals. Investigating the 95\%-confidence intervals of the indirect effects confirmed the moderated mediation: Appearance goals mediated the effect of the appearance goal condition on cheating in the social norm condition $(b=0.17,95 \%$ $\mathrm{CI}=[0.02 ; 0.46])$. This means that the experimental manipulation led to increased appearance goals, which were in turn associated with an increased rate of cheating when the confederate cheated as well. We found no such mediation when the confederate was

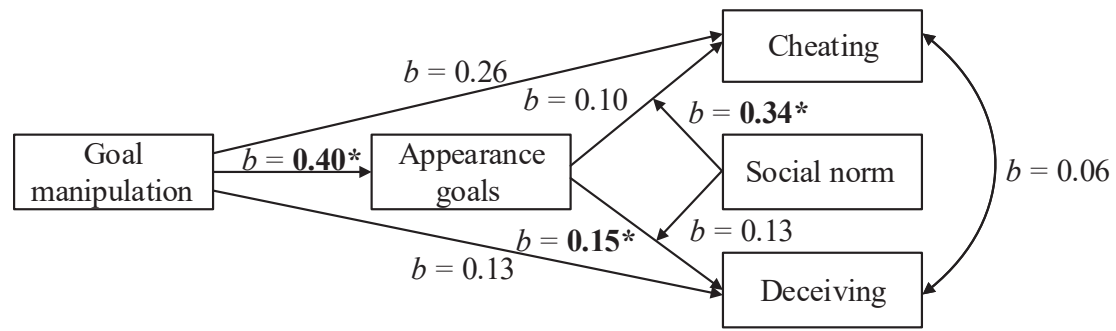

Figure 3. Overall moderated mediation model. $N=105 . \chi^{2}=2.03, p=.36, \mathrm{CFI}=.998, \mathrm{TLI}=.986$, RMSEA $=.012$. Goal manipulation represents whether appearance goals were induced: yes $(\mathrm{I})$ or no $(0)$. Reported are unstandardized coefficients. ${ }^{*} p<.05$. 
not cheating $(b=0.04,95 \% \mathrm{CI}=[-0.03 ; 0.18])$. For deceiving, the mediation effect was statistically significant for both conditions $(b \geq 0.06,95 \% \mathrm{CI}=[0.001 ; 0.31]){ }^{2}$

\section{Discussion}

In our experiment, we examined how peer cheating moderates the effects of induced appearance goals on cheating and deceiving. The strengths of the study include its preregistered experimental design, the objective measure of cheating, and the inclusion of deceiving as a second aspect of academic dishonesty. We found that appearance goals are only associated with increased cheating behaviour in a social environment that encourages cheating (strong social norm through cheating confederate), while for deceiving the social context proved to be less central as participants deceived more when their appearance goal striving was prompted regardless of the behaviour of other students. Our findings largely confirm our hypotheses and indicate the merits of including social norms as a moderator to better understand the effects of appearance goals on dishonest behaviours in achievement settings.

The findings on cheating behaviour strongly support our argument that it is important to consider the circumstances under which performance goals may translate into cheating behaviour. This might reflect that cheating becomes a more viable approach to making a good impression when the cheating of others indicates that this is an acceptable form of behaviour that is likely not harshly judged by one's surroundings. Here, we merely investigated the interaction between appearance approach goals and social norms. It may also be of importance to take performance goals characterized by an avoidance goal valence more strongly into account (for which we also found mixed results in our literature review). However, we think that the relationship between these goals and dishonest behaviour is very complex given that individuals with a strong avoidance focus might also fear the detection of their behaviour by others to a great extent, which could undermine the otherwise stimulating influence of appearance goals on dishonest behaviour (see especially Janke et al., 2019).

When elaborating on the findings regarding deceiving, it needs to be noted that the students only observed the confederate student cheat (but not deceive), which could explain the lacking interaction. When interpreting our findings, it needs to be borne in mind that we included deceiving as a second, not directly self-reported aspect of academic dishonesty that was inspired by prior research on the matter (Guadagno et al., 2012). However, this has not often been addressed or measured in previous research. We have to consider that systematic deviations in participants' answers to the personality questions might not solely measure their intended deceiving, but could also be biased by an array of other factors, such as certain personality traits being particularly salient in the situation or self-reflected upon or unintended self-deceiving to protecting one's self-worth. As such, our findings on deceiving need to be interpreted with some caution. Despite this, they can be taken as an indication that cheating and deceiving express rather different aspects of dishonesty (as also seen in their small correlation). Furthermore, considering deceiving measures might constitute another opportunity for future research to include measures of

\footnotetext{
${ }^{2}$ We also conducted a set of simpler analyses to ensure the robustness of the mediation effects using the PROCESS macro (Hayes, 2018) for SPSS by dividing our sample into two groups alongside the social norm manipulation. The results of these analyses yielded similar effects as the moderated mediation model. The only differences were that we did not find the mediation from appearance goal manipulation via appearance goals onto deceiving for the non-social norm manipulation group, but only for the social norm manipulation group.
} 
academic dishonesty that are not limited to self-reported behaviour in order to overcome limitations of most prior works on this issue.

Descriptively, our results showed a rather high amount of academic dishonesty in the knowledge test (cheating prevalence: 39\%), which is in line with the high amount of academic dishonesty frequently noted in the literature (63-94\% of students cheat at least once throughout their studies, across different study programmes, countries, and populations; Bernardi et al., 2004; Hrabak et al., 2004; McCabe, 2005; Rettinger et al., 2004; Teixeira \& Rocha, 2010). At the same time, the range of cheating behaviour between the different groups as well as the substantial variance observed in the deceiving measure indicated that the assessment centre cover story used in the experiment is well suited to investigate differences between individuals in their dishonest behaviours. This is especially so, as only one out of all participants detected our actual research aim, while all other students believed the cover story. Additionally, the manipulation of appearance goals worked well in this context. As such, this constitutes a sensible paradigm that can be well used in future research on this topic.

\section{Implications for future research and practical implications}

Taken together, these findings present strong experimental evidence that moderators such as social norms matter for the effects of performance goals on academic dishonesty. Our research further solidifies the notion that the inconsistency in associations between performance goals and dishonest behaviour may be partly due to uninvestigated moderator variables rooted in the situation, such as the presence of social norms, or rooted in the individual, such as adherence to such norms (see Janke et al., 2019). This assumption could and should motivate a new line of thinking about achievement goals and academic dishonesty that future research should follow up on. In future studies, researchers might also consider further moderators of the association between performance goals and academic dishonesty, such as the ascribed capability to engage in cheating behaviour, to advance our understanding of how personal performance goals translate into dishonest behaviours in educational settings. This would allow for additional reflection on the importance of perceived behavioural control, which could also substantially influence the relationship between performance goals and cheating in line with the Theory of Planned Behavior (Ajzen, 1991).

In addition, a particularly promising direction for future research would entail a naturalistic multilevel approach in which social norms are identified on the classroom level. In this context, it could also be promising to include classroom goal structure as an important predictor of personal achievement goals. While previous works on academic dishonesty have looked at classroom goal structures and personal achievement goals together and have provided important insights into the individual and joint influence of these constructs (Murdock et al., 2004, 2007), specifically testing and following up on the mediating role of personal achievement goals seems to hold great potential in this context - both for practical implications and our understanding of the motivational processes underlying academic dishonesty. Furthermore, beyond their relevance for personal achievement goals, different classroom goal structures might also stress different social norms. Prior research has, for instance, suggested that a performance goal structure can enhance the perceived acceptability of cheating (Murdock et al., 2004). As such, performance goal structures could be more consistently predictive for dishonesty than personal performance goals. Nevertheless, it is highly plausible that additional social cues (e.g., peer cheating, teachers' policies regarding the punishment of cheating) can 
diminish the association between performance goal structures and social acceptability, which would then allow for the investigation of the respective influence of social norms and classroom goal structures.

Regarding practical implications, our results imply that although certain achievement situations (that are characterized by a focus on, and rewards for, the impression that individuals make) may enhance appearance goals, the effects of these goals may not translate into increased cheating if students perceive the peer cheating rate and its acceptability to be low. Specifically, contextual cues like social norms appear crucial for the impact of individual appearance goals on cheating. This means that educators may be able to reduce cheating behaviour in high-stakes performance situations (in which it is not always possible to reduce performance goals) by inducing the right social norms (e.g., by rewarding role models of honest behaviour).

\section{Limitations}

Although the presented study has many strengths, there are limitations that should be considered when interpreting our findings. Most notably, we had a rather small sample size with rather narrow sample characteristics (mostly female, from similar study programmes of one university). While we believe that the investigated psychological mechanisms should be robust for different groups of participants, future research should follow up on our findings in less competitive settings, different fields, as well as different age and gender compositions to ensure generalizability. Furthermore, it needs to be borne in mind that the confederate student remained in the room, which might have reduced the actual rate of dishonesty. Finally, it is possible that our manipulation did not influence appearance goals directly but indirectly through induced extrinsic motivation as we also highlighted extrinsic rewards (see Janke \& Dickhäuser, 2018, 2019, for further elaborations on the association between achievement goals and extrinsic motivation). This is an important notion for future research into how the interplay of extrinsic motivation and appearance goals influences cheating.

\section{Conclusion}

While more research is needed on the practical implications of our results as well as on additional moderators (e.g., behavioural control) and mediators (e.g., extrinsic motivation), we think that our study provides important first insights into the relevance of social norms for the effects of appearance goals on cheating behaviour. This is particularly significant because the more that staff and administrators understand under which circumstances appearance goals translate into academic dishonesty, the more effectively they can create environments of integrity.

\section{References}

Ajzen, I. (1991). The theory of planned behavior. Organizational Behavior and Human Decision Processes, 50, 179-211. https://doi.org/10.1016/0749-5978(91)90020-T

Ames, C., \& Ames, R. (1984). Systems of student and teacher motivation: Toward a qualitative definition. Journal of Educational Psychology, 76, 535-556.

Anderman, E. M. (2007). The effects of personal, classroom, and school goal structures on academic cheating. In E. M. Anderman \& T. B. Murdock (Eds.), Psychology of academic cheating (pp. $87-$ 106). New York, NY: Academic Press. 
Anderman, E. M., Griesinger, T., \& Westerfield, G. (1998). Motivation and cheating during early adolescence. Journal of Educational Psychology, 90, 84-93. https://doi.org/10.1037/00220663.90 .1 .84

Benmansour, N. (2000). Motivation, satisfaction, success attributions and cheating among high school students in Morocco. Mediterranean Journal of Educational Studies, 5(2), 83-102.

Bernardi, R. A., Metzger, R. L., Bruno, R. G., Hoogkamp, M. A., Reyes, L. E., \& Barnaby, G. H. (2004). Examining the decision process of students' cheating behavior: An empirical study. Journal of Business Ethics, 50, 397-414. https://doi.org/10.1023/B:BUSI.0000025039.47788.c2

Bong, M. (2008). Effects of parent-child relationships and classroom goal structures on motivation, help-seeking avoidance, and cheating. The Journal of Experimental Education, 76, 191-217. https://doi.org/10.3200/JEXE.76.2.191-217

Cialdini, R. B., \& Trost, M. R. (1998). Social influence: Social norms, conformity and compliance. In D. T. Gilbert, S. T. Fiske, \& G. Lindzey (Eds.), The handbook of social psychology (pp. 151-192). New York, NY: McGraw-Hill.

Daumiller, M., Dickhäuser, O., \& Dresel, M. (2019). University instructors' achievement goals for teaching. Journal of Educational Psychology, 111, 131-148. https://doi.org/10.1037/ed u0000271

Dweck, C. S., \& Leggett, E. L. (1988). A social-cognitive approach to motivation and personality. Psychological Review, 95, 256-273. https://doi.org/10.1037/0033-295X.95.2.256

Elliot, A. J. (2005). A conceptual history of the achievement goal construct. In A. J. Elliot \& C. S. Dweck (Eds.), Handbook of competence and motivation (pp. 52-72). New York, NY: Guilford.

Elliot, A. J., \& McGregor, H. A. (2001). A $2 \times 2$ achievement goal framework. Journal of Personality and Social Psychology, 80, 501-519. https://doi.org/10.1037/0022-3514.80.3.501

Fehr, E., \& Fischbacher, U. (2004). Third-party punishment and social norms. Evolution and Human Behavior, 25, 63-87. https://doi.org/10.1016/S1090-5138(04)00005-4

Genereux, R. L., \& McLeod, B. A. (1995). Circumstances surrounding cheating: A questionnaire study of college students. Research in Higher Education, 36, 687-704. https://doi.org/10. 1007/BF02208251

Giluk, T., \& Postlethwaite, B. (2015). Big five personality and academic dishonesty: A meta-analytic review. Personality and Individual Differences, 72, 59-67. https://doi.org/10.1016/j.paid. 2014.08.027

Gino, F., Ayal, S., \& Ariely, D. (2009). Contagion and differentiation in unethical behavior: The effect of one bad apple on the barrel. Psychological Science, 20, 393-398. https://doi.org/10.1111/j. 1467-9280.2009.02306.x

Graham, M. A., Monday, J., O’Brien, K., \& Steffen, S. (1994). Cheating at small colleges: An examination of student and faculty attitudes and behaviors. Journal of College Student Development, 35, 255-260.

Guadagno, R. E., Okdie, B. M., \& Kruse, S. (2012). Dating deception: Gender, online dating, and exaggerated self-presentation. Computers in Human Behavior, 28, 642-647. https://doi.org/ 10.1016/j.chb.2011.11.010

Haines, V. J., Diekhoff, G. M., LaBeff, E. E., \& Clark, R. E. (1986). College cheating: Immaturity, lack of commitment, and the neutralizing attitude. Research in Higher Education, 25, 342-354. https://doi.org/10.1007/BF00992130

Hayes, A. F. (2018). Introduction to mediation, moderation, and conditional process analysis (2nd ed.). New York, NY: The Guilford Press.

He, T.-H., Gou, W. J., \& Chang, S.-M. (2015). Parental involvement and elementary school students' goals, maladaptive behaviors, and achievement in learning English as a foreign language. Learning and Individual Differences, 39, 205-210. https://doi.org/10.1016/j.lindif.2015.03.011

Hrabak, M., Vujaklija, A., Vodopivec, I., Hren, D., Marusić, M., \& Marusić, A. (2004). Academic misconduct among medical students in a post-communist country. Medical Education, 38, 276285. https://doi.org/10.1111/j.1365-2923.2004.01766.x

Huang, C.-L., Shu Ching, Y., \& An-Sing, C. (2015). The relationships among students' achievement goals, willingness to report academic dishonesty, and engaging in academic dishonesty. Social 
Behavior E Personality: An International Journal, 43, 27-38. https://doi.org/10.2224/sbp. 2015.43.1.27

Hulleman, C. S., Schrager, S. M., Bodmann, S. M., \& Harackiewicz, J. (2010). A meta-analytic review of achievement goal measures: Different labels for the same constructs or different constructs with similar labels? Psychological Bulletin, 136, 422-449. https://doi.org/10.1037/a0018947

Huss, M. T., Curnyn, J. P., Roberts, S. L., \& Davis, S. F. (1993). Hard driven but not dishonest: Cheating and the Type A personality. Bulletin of the Psychonomic Society, 31, 429-430. https://doi.org/ $10.3758 / \mathrm{bf0} 0334952$

Janke, S., Daumiller, M., \& Rudert, S. (2019). Dark pathways to achievement in science: Re-searchers' achievement goals predict engagement in questionable research practices. Social Psychological and Personality Science, 10, 783-791. https://doi.org/10.1177/1948550618790227

Janke, S., \& Dickhäuser, O. (2018). A situated process model of vocational achievement goal striving within members of the academic staff at university. Motivation and Emotion, 42, 466-481. https://doi.org/10.1007/s11031-017-9657-z

Janke, S., \& Dickhäuser, O. (2019). A neglected tenet of achievement goal theory: Associations between life aspirations and achievement goal orientations. Personality and Individual Differences, 142, 90-99. https://doi.org/10.1016/j.paid.2019.01.038

Jordan, A. E. (2001). College student cheating: The role of motivation, perceived norms, attitudes, and knowledge of institutional policy. Ethics \& Behavior, 11, 233-247. https://doi.org/10. 1207/S15327019EB1103_3

Keith-Spiegel, P., \& Whitley, B. (2012). Academic dishonesty: An educator's guide (2nd ed.). New York, NY: Psychology Press.

Kibler, W. L., \& Kibler, P. V. (1993). When students resort to cheating. The Chronicle of Higher Education, 39(45), B1-B2.

Koul, R. (2012). Multiple motivational goals, values, and willingness to cheat. International Journal of Educational Research, 56, 1-9. https://doi.org/10.1016/j.ijer.2012.10.002

Küfner, A. C., Dufner, M., \& Back, M. D. (2014). Das Dreckige Dutzend und die Niederträchtigen Neun: Kurzskalen zur Erfassung von Narzissmus, Machiavellismus und Psychopathie [The Dirty Dozen and the Naughty Nine: Short scales for the assessment of narcissism, Machiavellianism, and psychopathy]. Diagnostica, 61, 76-91. https://doi.org/10.1026/0012-1924/a000124

Lawson, R. A. (2004). Is classroom cheating related to business students' propensity to cheat in the "real world"? Journal of Business Ethics, 49, 189-199. https://doi.org/10.1023/B:BUSI. 0000015784.34148.cb

Little, R. J. (1988). A test of missing completely at random for multivariate data with missing values. Journal of the American statistical Association, 83, 1198-1202. https://doi.org/10.1080/ 01621459.1988 .10478722

Lüftenegger, M., Tran, U. S., Bardach, L., Schober, B., \& Spiel, C. (2017). Measuring a mastery goal structure using the TARGET framework: Development and validation of a classroom goal structure questionnaire. Zeitschrift für Psychologie, 225, 64-75. https://doi.org/10.1027/21512604/a000277

Marsden, H., Carroll, M., \& Neill, J. T. (2005). Who cheats at university? A self-report study of dishonest academic behaviours in a sample of Australian university students. Australian Journal of Psychology, 57, 1-10. https://doi.org/10.1080/00049530412331283426

McCabe, D. L. (2005). It takes a village: Academic dishonesty \& educational opportunity. Liberal Education, 91(1), 26-31.

McCabe, D. L., \& Treviño, L. K. (1997). Individual and contextual influences on academic dishonesty: A multicampus investigation. Research in Higher Education, 38, 379-396. https://d oi.org/10.1023/A:1024954224675

McCabe, D. L., Trevino, L. K., \& Butterfield, K. D. (1999). Academic integrity in honor code and non-honor code environments: A qualitative investigation. The Journal of Higher Education, 70, 211-234. https://doi.org/10.1080/00221546.1999.11780762

McCabe, D. L., Treviño, L. K., \& Butterfield, K. D. (2001). Cheating in academic institutions: A decade of research. Ethics \& Behavior, 11, 219-232. https://doi.org/10.1207/s15327019eb1103_2 
Meece, J. L., Anderman, E. M., \& Anderman, L. H. (2006). Classroom goal structure, student motivation, and academic achievement. Annual Review of Psychology, 57, 487-503. https://d oi.org/10.1146/annurev.psych.56.091103.070258

Murdock, T. B., \& Anderman, E. M. (2006). Motivational perspectives on student cheating: Toward an integrated model of academic dishonesty. Educational Psychologist, 41, 129-145. https://d oi.org/10.1207/s15326985ep4103_1

Murdock, T. B., Hale, N. M., \& Weber, M. J. (2001). Predictors of cheating among early adolescents: Academic and social motivations. Contemporary Educational Psychology, 26, 96-115. https://doi.org/10.1006/ceps.2000.1046

Murdock, T. B., Miller, A. D., \& Goetzinger, A. (2007). Effects of classroom context on university students' judgments about cheating: Mediating and moderating processes. Social Psychology of Education, 10, 141-169. https://doi.org/10.1007/s11218-007-9015-1

Murdock, T. B., Miller, A., \& Kohlhardt, J. (2004). Effects of classroom context variables on high school students' judgments of the acceptability and likelihood of cheating. Journal of Educational Psychology, 96, 765-777. https://doi.org/10.1037/0022-0663.96.4.765

Musch, J., Brockhaus, R., \& Bröder, A. (2002). Ein Inventar zur Erfassung von zwei Faktoren sozialer Erwünschtheit [An inventory for the assessment of two factors of social desirability]. Diagnostica, 48, 121-129. https://doi.org/10.1026//0012-1924.48.3.121

Niiya, Y., Ballantyne, R., North, M. S., \& Crocker, J. (2008). Gender, contingencies of self-worth, and achievement goals as predictors of academic cheating in a controlled laboratory setting. Basic and Applied Social Psychology, 30, 76-83. https://doi.org/10.1080/01973530701866656

Nonis, S., \& Swift, C. O. (2001). An examination of the relationship between academic dishonesty and workplace dishonesty: A multicampus investigation. Journal of Education for Business, 77 , 69-77. https://doi.org/10.1080/08832320109599052

O'Rourke, J., Barnes, J., Deaton, A., Fulks, K., Ryan, K., \& Rettinger, D. A. (2010). Imitation is the sincerest form of cheating: The influence of direct knowledge and attitudes on academic dishonesty. Ethics \& Behavior, 20, 47-64. https://doi.org/10.1080/10508420903482616

Pavlin-Bernardić, N., Rovan, D., \& Pavlović, J. (2017). Academic cheating in mathematics classes: A motivational perspective. Ethics \& Behavior, 27, 486-501. https://doi.org/10.1080/10508422. 2016.1265891

Peklaj, C., Kalin, J., Pečjak, S., Valenčič Zuljan, M., \& Puklek Levpušček, M. (2012). Perceptions of teachers' goals in classroom, students' motivation and their maladaptive behaviour as predictors of high school math achievement. Studia Psychologica, 54, 329-344.

Peugh, J. L., \& Enders, C. K. (2004). Missing data in educational research: A review of reporting practices and suggestions for improvement. Review of Educational Research, 74, 525-556. https://doi.org/10.3102/00346543074004525

Poortvliet, M. P., Janssen, O., Van Yperen, N. W., \& Van de Vliert, E. (2007). Achievement goals and interpersonal behavior: How mastery and performance goals shape information exchange. Personality and Social Psychology Bulletin, 33, 1435-1447

Rammstedt, B., \& John, O. P. (2005). Kurzversion des Big Five Inventory (BFI-K) [Short version of the Big Five Inventory (BFI-K): Development and validation of an economic inventory for assessment of the five factors of personality]. Diagnostica, 51, 195-206. https://doi.org/10.1026/0012-1924.51.4.195

Rettinger, D. A., \& Jordan, A. E. (2005). The relations among religion, motivation, and college cheating: A natural experiment. Ethics \& Behavior, 15, 107-129. https://doi.org/10.1207/ s15327019eb1502_2

Rettinger, D. A., Jordan, A. E., \& Peschiera, F. (2004). Evaluating the motivation of other students to cheat: A vignette experiment. Research in Higher Education, 45, 873-890. https://doi.org/10. 1007/s11162-004-5952-0

Rettinger, D. A., \& Kramer, Y. (2009). Situational and personal causes of student cheating. Research in Higher Education, 50, 293-313. https://doi.org/10.1007/s11162-008-9116-5

Rudert, S. C., Sutter, D., Corrodi, V. C., \& Greifeneder, R. (2018). Who's to blame? Dissimilarity as a cue in moral judgments of observed ostracism episodes. Journal of Personality and Social Psychology, 115, 31-53. https://doi.org/10.1037/pspa0000122 
Schermelleh-Engel, K., Moosbrugger, H., \& Müller, H. (2003). Evaluating the fit of structural equation models. Methods of Psychological Research-Online, 8, 23-74. https://doi.org/10.1.1. 509.4258

Schwieren, C., \& Weichselbaumer, D. (2010). Does competition enhance performance or cheating? A laboratory experiment. Journal of Economic Psychology, 31, 241-253. https://doi.org/10. 1016/j.joep.2009.02.005

Sicak, A., \& Arslan, A. (2016). The relation between prospective teachers' goal orientations and academic e-dishonesty. Universal Journal of Educational Research, 4, 1660-1666. https://doi. org/10.13189/ujer.2016.040718

Simkin, M. G., \& McLeod, A. (2010). Why do college students cheat? Journal of Business Ethics, 94 , 441-453. https://doi.org/10.1007/s10551-009-0275-x

Stephens, J. M. (2008). Cheating. In N. J. Salkind (Ed.), Encyclopedia of educational psychology (pp. 136-142). Los Angeles, CA: Sage.

Stephens, J. M., \& Gehlbach, H. (2007). Under pressure and underengaged: Motivational profiles and academic cheating in high school. In E. Anderman \& T. Murdock (Eds.), Psychology of academic cheating (pp. 107-134). Burlington, MA: Academic Press.

Stephens, J. M., Romakin, V., \& Yukhymenko, M. (2010). Academic motivation and misconduct in two cultures: A comparative analysis of US and Ukrainian undergraduates. International Journal for Educational Integrity, 6(1), 47-60.

Sykes, G. M., \& Matza, D. (1957). Techniques of neutralization: A theory of delinquency. American Sociological Review, 22, 664-670.

Tas, Y., \& Tekkaya, C. (2010). Personal and contextual factors associated with students' cheating in science. Journal of Experimental Education, 78, 440-463. https://doi.org/10.1080/ 00220970903548046

Teixeira, A. A., \& Rocha, M. F. (2010). Cheating by economics and business undergraduate students: An exploratory international assessment. Higher Education, 59, 663-701. https://doi.org/10. 1007/s10734-009-9274-1

Tyler, K. M. (2015). Examining cognitive predictors of academic cheating among urban middle school students: The role of home-school dissonance. Middle Grades Research Journal, 10(3), 77-93.

Urdan, T., \& Mestas, M. (2006). The goals behind performance goals. Journal of Educational Psychology, 98, 354-365. https://doi.org/10.1037/0022-0663.98.2.354

Van Yperen, N. W., Hamstra, M. R., \& van der Klauw, M. (2011). To win, or not to lose, at any cost: The impact of achievement goals on cheating. British Journal of Management, 22, 5-15. https://doi.org/10.1111/j.1467-8551.2010.00702.x

Vansteenkiste, M., Smeets, S., Soenens, B., Lens, W., Matos, L., \& Deci, E. L. (2010). Autonomous and controlled regulation of performance-approach goals: Their relations to perfectionism and educational outcomes. Motivation and Emotion, 34, 333-353. https://doi.org/10.1007/ s11031-010-9188-3

Whitley, B. (1998). Factors associated with cheating among college students: A review. Research in Higher Education, 39, 235-274. https://doi.org/10.1023/A:1018724900565.pdf

Received I2 December 2018; revised version received 21 June 2019

\section{Supporting Information}

The following supporting information may be found in the online edition of the article:

Table S1. Correlations for all reported variables.

Appendix S1. Complete knowledge test administered to the students (please note that the test was administered in German, the English translations are not validated and some of the knowledge questions may not work very well outside of Germany). 